\title{
Effects of Wetness Duration and Grain Development Stages on Sorghum Grain Mold Infection
}

\author{
S. S. Navi, Plant Pathology Department, 351 Bessey Hall, Iowa State University (ISU), Ames 50011, USA; \\ R. Bandyopadhyay, International Institute of Tropical Agriculture, PMB 5320, Ibadan, Nigeria; R. K. Reddy and \\ R. P. Thakur, International Crops Research Institute for the Semi-Arid Tropics, Patancheru, P.O. Andhra Pradesh, \\ 502 324, India; and X. B. Yang, Plant Pathology Department, 351 Bessey Hall, ISU, Ames 50011, USA
}

\begin{abstract}
Navi, S. S., Bandyopadhyay, R., Reddy, R. K., Thakur, R. P., and Yang, X. B. 2005. Effects of wetness duration and grain development stages on sorghum grain mold infection. Plant Dis. 89:872-878.

Grain mold caused by a complex of fungi is an economically important disease of sorghum worldwide. Little is known about the epidemiology of sorghum grain mold, which is essential for its management. Studies were conducted to quantify the effects of wetness duration on grain mold development under controlled conditions at ICRISAT. Six major sorghum grain mold fungi determined from previous field experiments, Curvularia lunata, Cladosporium oxysporum, Bipolaris australiensis, Fusarium moniliforme, F. pallidoroseum, and Phoma sorghina, were used. Panicles of a pot-grown mold-susceptible sorghum line, IS 10513, were spray inoculated with each fungus at five growth stages: flowering (F), milk (M), soft dough (S), hard dough (H), and physiological maturity $(\mathrm{P})$, and were incubated in dew chambers for $0,16,24,40,48$, and $72 \mathrm{~h}$. Then, the plants were placed on greenhouse benches at $25 \pm 1^{\circ} \mathrm{C}$ to allow grain mold infection to develop. Eight days after treatments, grains from F, M, and $\mathrm{S}$ stages were plated onto potato dextrose agar, while those from $\mathrm{H}$ and $\mathrm{P}$ stages were incubated in blotter paper humid chambers at $28 \pm 1{ }^{\circ} \mathrm{C}$. Fungal colonization of grains were scored after 7 days. Results indicated a significant $(P<0.01)$ correlation between wetness duration and grain mold development at different stages of inoculation. Generally, with increasing wetness duration, there was an increase in grain infection by all six fungi. However, infection frequency varied among fungi and grain development stages, indicating that individual fungi might have different windows for maximum infection during the grain development stages.
\end{abstract}

Additional keywords: growth stages, infection frequency, major mold fungi

In many regions of the world where sorghum (Sorghum bicolor (L.) Moench) is produced, grain mold is a serious disease that reduces grain quality and utilization. The term "grain mold" is used to describe the diseased appearance of sorghum grain resulting from infection by one or more parasitic fungal species (21). Grain mold is most commonly caused by Fusarium moniliforme J. Sheld. and Curvularia lunata (Wakk.) Boedjin, although many other fungal species are also associated with the mold complex $(9,16)$. It is a major biotic constraint to sorghum improvement and production worldwide, especially when grain development coincides with wet and warm weather conditions (10). It is estimated that annual economic losses in Asia and Africa as a result of grain mold are in excess of US $\$ 130$ million (13). In some cases, yield losses can reach $100 \%$ in

Corresponding author: S. S. Navi

E-mail: ssnavi@iastate.edu

Accepted for publication 25 April 2005.

DOI: 10.1094/PD-89-0872

(C) 2005 The American Phytopathological Society highly susceptible cultivars (12). Apart from yield reduction, grain mold also reduces seed quality, with effects ranging from cosmetic deterioration of the pericarp to substantial deterioration of the endosperm and embryo with reduction in acceptability by food and feed processors (17). In addition to reducing the nutritional value, fungi that cause grain mold in sorghum may also produce mycotoxins (7), thus limiting the use of sorghum grain as food and feed (16). Molded sorghum grain fetches lower market prices and therefore affects the income of sorghum farmers (2).

Certain grain mold pathogens have frequently been associated with losses in seed mass $(7,19)$, grain density $(6,12)$, germination $(6,15)$, storage quality (11), food and feed processing quality, and market value (3). Severely affected grains have poor quality and become unsuitable for human and animal consumption because of toxins produced by some of the fungi. Little is known about the epidemiology of sorghum grain mold, which is essential for its management.

Association of Fusarium spp. and Aspergillus spp. with sorghum and maize has been a major cause of concern because of their ability to produce toxins $(4,5)$. Grain mold has been a continuous problem in the semi-arid tropics in India, Africa, and the Americas. The most pathogenic field fungi that seriously damage grain in sorghum are F. moniliforme and Curvularia lunata $(8,21)$. They invade the young, developing kernels, colonizing from the base toward the tip. The primarily saprophytic fungi that invade mature kernels, colonizing from parts of the kernel not covered by the glumes and progressing toward the base, include most frequently Cladosporium spp., Alternaria spp., and Phoma spp. $(8,21)$, although several genera have been isolated from sorghum grain $(8,16,21)$. Some important toxins produced by $F$. moniliforme, such as fumonisins, moniliformin, fusaproliferin, fusaric acid, fusarins, beauvericin, and gibberlic acids by fungi belonging to Liseola section of the genus Fusarium, have been reported by Leslie (14). No reports are available on toxin production by other fungi listed in the study.

Bipolaris australiensis (M.B. Ellis) Tsuda \& Ueyama is a widespread fungus that is most frequently associated with grasses, plant material, and soil. It has also been reported as an infrequent agent of phaeohyphomycosis, particularly fungal sinusitis. Cladosporium sp. is most commonly identified as an outdoor fungus. The outdoor numbers are reduced in the winter while often high in the summer. Often found indoors in numbers less than outdoor numbers, it is a common allergen. It can occasionally cause a corneal infection of the eye (1). Indoor Cladosporium sp. may be different than the species identified outdoors. It is commonly found on the surface of fiberglass lining in the interior of supply ducts. A wide variety of plants serve as food sources for this fungus. It is found on dead and woody plants, food, straw, soil, paint, and textiles. It can cause mycosis, and produces more than 10 antigens. Antigens in commercial extracts are of variable quality and may degrade within weeks of preparation. A common cause of extrinsic asthma (immediate-type hypersensitivity: type I), acute symptoms include edema and bronchiospasms, while some chronic cases may develop into pulmonary emphysema (1). Curvularia spp. have also been reported to be allergenic. They, too, may cause corneal infections, mycetoma, and infections in immune compromised hosts (1). Although grain mold is 
associated with sorghum that matures during conditions of wet weather, published reports on quantitative relationships between weather variables and mold are limited. An in vitro screening technique for grain mold resistance (18) and a field screening technique using overhead sprinklers (3) have been developed; however, the influence of wetness duration during the development stages on grain mold caused by individual fungi have not been fully determined. Therefore, this study was carried out at ICRISAT, Patancheru, India, to determine the effects of wetness duration on infection by various grain mold fungi at different grain development stages of sorghum.

\section{MATERIALS AND METHODS}

Isolation and maintenance of fungi. Molded sorghum grains were collected in the 1999 rainy season at the ICRISAT research farm (Hyderabad, Andhra Pradesh, India). Grains were surface sterilized in $0.1 \% \mathrm{HgCl}_{2}$ for $2 \mathrm{~min}$, washed in sterile distilled water (SDW) three times, and transferred to 9-cm-diameter petri dishes containing potato dextrose agar (PDA) and incubated at $28 \pm 1{ }^{\circ} \mathrm{C}$ in a 12 -h photoperiod for 5 days. Pure cultures of Curvularia lunata, Cladosporium oxysporum Berk. \& Curt., B. australiensis, Fusarium moniliforme, $F$. pallidoroseum (Cooke) Sacc., and Phoma sorghina (Sacc.) Boerema, Dorenbosch, \& van Kesteren were isolated and maintained on PDA by subculturing at 30-day intervals for the study.

For inoculum production, isolated fungi were cultured separately on autoclaved sorghum grains of Bulk-Y in conical flasks as follows. Clean grains of Bulk-Y (50 g) were placed in $150-\mathrm{ml}$ conical flasks, soaked in SDW overnight, and the excess water drained off. The flasks were sterilized at $121^{\circ} \mathrm{C}, 15 \mathrm{PSI}$ for $15 \mathrm{~min}$ and inoculated separately with each of the isolated fungi. The flasks were incubated on laboratory benches at $26 \pm 1{ }^{\circ} \mathrm{C}$ for 2 weeks. During this period, the flasks were shaken every alternate day to encourage uniform growth of fungi on all grains.

Planting. Seeds of early maturing dwarf sorghum line IS 10513 were surface sterilized in $1 \%$ sodium hypochlorite (commercial bleach containing $5.25 \%$ sodium hypochlorite) and planted in $22-\mathrm{cm}$-diameter round plastic pots filled with vertisol. To achieve flowering (F), milk (M), soft dough (S), hard dough $(\mathrm{H})$, and physiological maturity (P) grain development stages at the same time for inoculation, seeds were planted in 7-day intervals. A total of 420 plants, six replications each with two plants for six fungi and a control, were used for a combination of six wetness durations (WD) within the five grain development stages.

Inoculum preparation and inoculation. Twenty grains, uniformly colonized with each fungus, were aseptically transferred to $50-\mathrm{ml}$ beakers containing $15 \mathrm{ml}$ of SDW. The beakers were covered with Parafilm (American National Can, Chicago, IL) and stirred on a magnetic stirrer (Fisher Scientific, Hampton, NH 03842, U.S.A.). The spore suspensions of $C$. $l u$ nata, Cladosporium oxysporum, B. australiensis, $F$. moniliforme, $F$. pallidoroseum, and $P$. sorghina were filtered separately through a sterilized tea strainer, and the spore concentration of each resultant suspension was adjusted to $1 \times 10^{5}$ conidia per $\mathrm{ml}$ using a hemacytometer. The suspension of each fungus was transferred separately to 200-ml capacity aerosol spray bottles (Nalgene Co., Rochester, NY 14602, U.S.A.) for spray inoculation. Two panicles were selected for each of the combinations of grain development stage, wetness duration, and fungus. The panicles selected were thoroughly shaken to remove anthers and other dust particles. Panicles were spray inoculated with $C$. lunata, Cladosporium oxysporum, B. australiensis, $F$. moniliforme, $F$. pallidoroseum, and $P$. sorghina at $1 \times 10^{5}$ conidia per $\mathrm{ml}$ using aerosol spray bottles, while those sprayed with DSW were maintained as controls. Appropriate care was taken for uniform inoculation of panicles and to avoid any contamination with other inocula, while the control panicles were water-sprayed. While inoculating, the selected panicles were covered with Kraft plain paper bags $(14 \times 6 \times 42 \mathrm{~cm})$, with the exception of the one under spray-inoculation. The inoculated plants of each fungus and SDW were moved to seven greenhouse chambers for air-drying. Two plants with uniform panicle size were maintained in each pot. Plants were labeled using plastic ribbons to detail plant number, growth stage, wetness duration, and fungus inoculated. The experiment was conducted three times.

Exposure to wetness duration. Upon inoculation and air-drying, the plants were classified into six groups, one group per wetness-duration (WD), and shifted to dew chambers stabilized with 16, 24, 40, 48, and $72 \mathrm{~h} \mathrm{WD}$ at $25 \pm 1^{\circ} \mathrm{C}$. Plants requiring zero WD were directly shifted to greenhouse benches. All plants were exposed to a uniform incubation period of 8 days at 25 $\pm 1^{\circ} \mathrm{C}$ in the greenhouse.

Assessment for infection by mold fungi. Eight days after the incubation, 50 grains per replication were sampled in surface sterilized mini-grip resealable bags $(6 \times 6 \mathrm{~cm})$, surface sterilized in $1 \%$ sodium hypochlorite, and rinsed with three washes in SDW. The grain samples from panicles inoculated at the F, M, and S stages were transferred to PDA (25 grains per plate). Those of $\mathrm{H}$ and $\mathrm{P}$ stages were transferred on sterilized petri dish humidity chambers under aseptic conditions (18). Petri dish humidity chambers were prepared by lining the lower lid with a thin layer of ab- sorbent cotton followed by two layers of blotter paper. The cotton-blotting papers were wetted with $15 \mathrm{ml}$ of distilled water. Upon covering the upper lid, the entire assembly was placed in a stainless steel sterilizing container (Fisher Scientific) and sterilized at $121^{\circ} \mathrm{C}$ and 15 PSI for $15 \mathrm{~min}$. The plates were incubated at $28 \pm 1^{\circ} \mathrm{C}$ for 5 days with a 12-h photoperiod and evaluated for infection based on symptoms observed on the grain surface (16). The infection frequency of each fungus was recorded.

Data analysis. Percent infection (\%) of all six fungi at all five grain development stages was calculated using Genstat statistical package (Rothamsted Experiment Station, Herpenden, UK), while regression curves of all six fungi at the five grain development stages were plotted using SigmaPlot 2001 (Aspire Software International, Leesburg, VA).

\section{RESULTS}

Fungal isolations. The most commonly occurring fungi on molded sorghum grains at ICRISAT research farm (based on infection frequency in earlier field studies at ICRISAT, unpublished) were $B$. australiensis, C. lunata, Cladosporium oxysporum, Fusarium moniliforme Lisea fujikuroi Sawada, F. pallidoroseum, and Phoma sorghina.

Effect of wetness duration and grain development stages on infection. No apparent mold symptoms were observed in panicles inoculated from $\mathrm{F}$ to $\mathrm{S}$ stages at the time of sampling, while the symptoms were visible on panicles inoculated at $\mathrm{H}$ and P. With a change in the grain development stage, there was a change in infection level by individual fungi (Fig. 1A to F). Of the six fungi inoculated at $\mathrm{F}$ stage, frequency $(\%)$ range of $F$. moniliforme was 15 to $50 \%$ when panicles were exposed to the wetness of 24 to $72 \mathrm{~h}$ followed by other fungi (Fig. 1A to F). However, there was an increased infection of all the fungi inoculated except $F$. moniliforme, in which maximum infection was observed when the panicles were exposed to 40 to $48 \mathrm{~h}$ WD (Fig. 1A to F).

Infection frequency of $\boldsymbol{C}$. lunata. The mean infection frequency of $C$. lunata in panicles inoculated at $\mathrm{F}$ stage was $16 \%$ compared with $82 \%$ at $\mathrm{P}$ stage (Fig. 1A). The panicles that were inoculated at $\mathrm{F}$ stage and not exposed to WD in dew chambers had an infection frequency of $2.8 \%$ compared with $34 \%$ with 72 h WD. Generally, infection (\%) of C. lunata increased with an increase in WD and grain development stages. There was $61 \%$ infection at $\mathrm{S}$ stage and $82 \%$ at $\mathrm{P}$ stage with 16h WD compared with 66 and $97 \%$, respectively, with 24-h WD. There was $100 \%$ infection at $\mathrm{P}$ stage with 48-h WD compared with $100 \%$ infection at $\mathrm{H}$ stage with 72-h WD, indicating the most favorable WD for $C$. lunata infection was between 
48 and $72 \mathrm{~h}$ with $\mathrm{H}$ and $\mathrm{P}$ stages, respectively.

Infection frequency of Cladosporium oxysporum. The infection frequency of Cladosporium oxysporum was similar to that of Curvularia lunata; however, the mean frequency of Cladosporium oxysporum at $\mathrm{F}$ stage was $20.5 \%$ compared with $74.6 \%$ at $P$ stage. Similarly, the rate of infection was slower in panicles inoculated at the F stage than in panicles inoculated at other grain development stages (Fig. 1B). Constant exposure of panicles inoculated at $M$ and $S$ stages for $72-h$ wetness have shown almost equal frequency when panicles were inoculated at $\mathrm{H}$ and $\mathrm{P}$ stages with 24-h wetness exposure (Fig. 1B). Generally, the infection frequency rate was lower in early grain development stages ( $F$ to $S$ ) than in late development stages ( $\mathrm{H}$ and $\mathrm{P}$ ), signifying that panicles inoculated at early grain development stages require higher wetness than panicles inoculated at later grain development stages. Unlike $C$. $l u$ nata, the infection frequency of Cladosporium oxysporum was higher at all grain development stages at zero wet- ness exposure. It appears that wetness exposure along with the inoculum may be adequate for higher infection frequency of Cladosporium oxysporum. However, highest mean infection frequency of $78.2 \%$ was observed in panicles inoculated at $\mathrm{H}$ stage than in panicles inoculated at $\mathrm{P}$ stage (Fig. 1B).

Similarly, the infection (\%) of Cladosporium oxysporum was similar to that of Curvularia lunata excepting being higher in $\mathrm{H}$ stage. However, there was $37 \%$ infection in S stage and $64 \%$ in $\mathrm{H}$ stage with 16-h WD, while with 24-, 48-, and 72-h
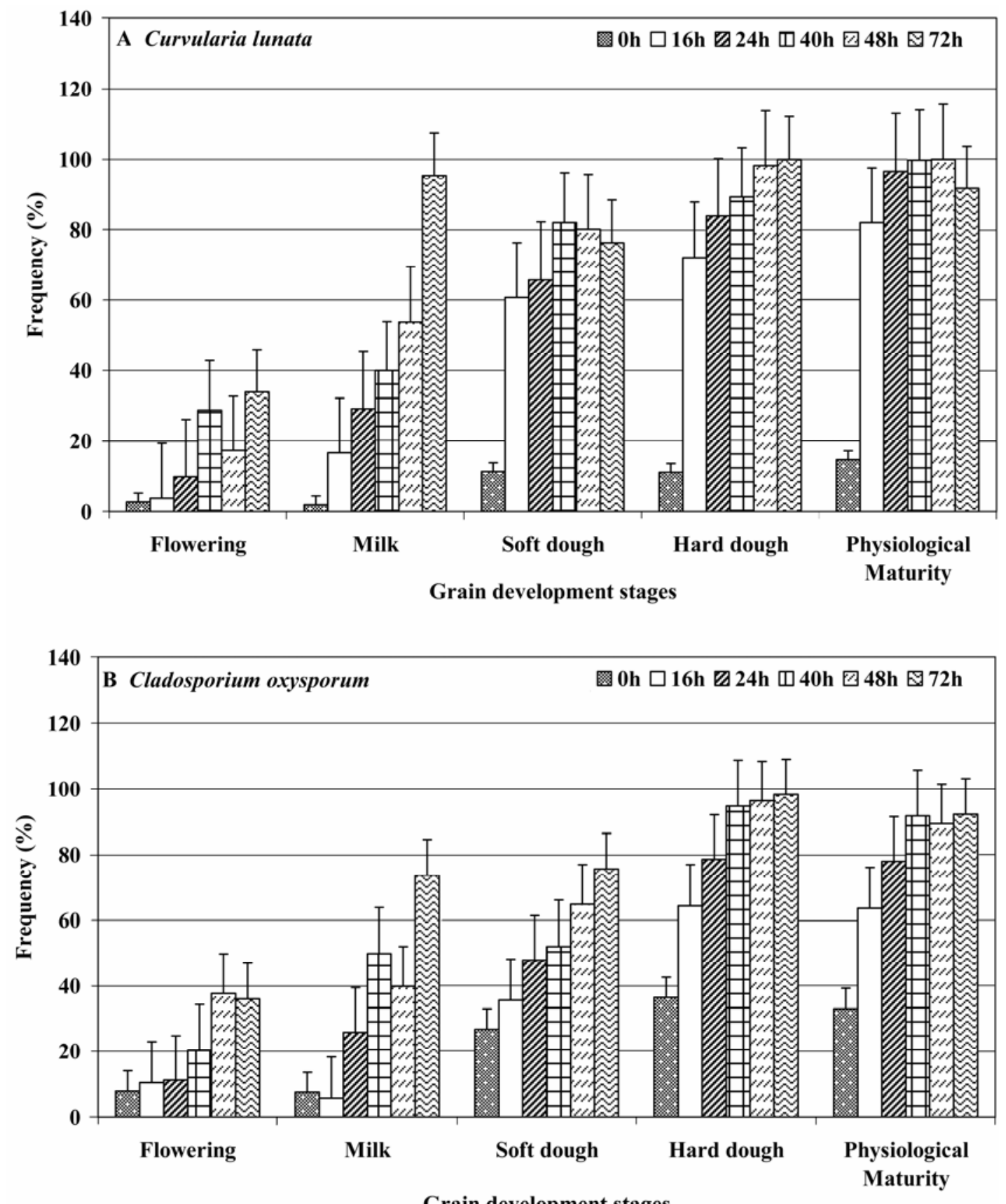

Grain development stages

(Continued on next page)

Fig. 1. Effect of wetness duration and grain development stages on infection (\%) of A, Curvularia lunata; B, Cladosporium oxysporum; $\mathbf{C}$, Bipolaris australiensis; D, Fusarium moniliforme; E, F. pallidoroseum; and $\mathbf{F}$, Phoma sorghina. The grains collected for isolation were from the panicles of sorghum line IS 10513 inoculated at flowering, milk, soft dough, hard dough, and physiological maturity stages. 
WD there was 48,65 , and $76 \%$ infection at S stage compared with 79,96 , and $98 \%$ at $\mathrm{H}$ stage, respectively. Interestingly, there was a consistent increase in infection both in $\mathrm{S}$ and $\mathrm{H}$ stages with increased WD, indicating the most favorable WD for the fungus was between 48 and $72 \mathrm{~h}$.

Infection frequency of $B$. australiensis. In the case of $B$. australiensis, unlike $C$. lunata and Cladosporium oxysporum, the infection frequency was consistently increasing with increased WD and grain development stage (Fig. 1C). B. australiensis recorded lower infection frequency than that of Cladosporium oxysporum at zero wetness. However, subsequent WDs of 16 to $72 \mathrm{~h}$ and $\mathrm{S}$ to $\mathrm{P}$ grain development stages have shown $>50 \%$ infection. A frequency level of $B$. australiensis was highest compared with the other four fungi tested when the panicles were exposed between 16- and 72-h WD (Fig. 1C). Interestingly, frequency levels of $B$. australiensis remained unchanged between $\mathrm{H}$ and $\mathrm{P}$ stages when the panicles were exposed to 48- and 72-h WD. It was observed that the infection frequency of $B$. australiensis was increasing with an increase in wetness duration (Fig. 1C). In the case of B. australiensis, unlike C. lunata and Cladosporium oxysporum, the infection (\%) was consistent with increased WD and grain development stages.
Infection frequency of $\boldsymbol{F}$. moniliforme. At zero WD, the infection frequency of $F$. moniliforme was similar to that of $B$. australiensis (Fig. 1D), whereas the infection frequency in panicles inoculated at $\mathrm{P}$ stage was similar to that of $C$. lunata. The mean infection frequency of $F$. moniliforme in panicles inoculated at $\mathrm{F}$ stage was $24.8 \%$ compared with $47.8,71.6,70.9$, and $77.9 \%$ in panicles inoculated at $\mathrm{M}, \mathrm{S}, \mathrm{H}$, and $\mathrm{P}$ stage, respectively. However, panicles inoculated at $M$ stage have shown little less infection frequency at 72-h WD than at 48-h WD (Fig. 1D). As was observed in C. lunata, Cladosporium oxysporum, and $B$. australiensis, infection frequency was lower in panicles inoculated at early grain

(Continued from previous page)
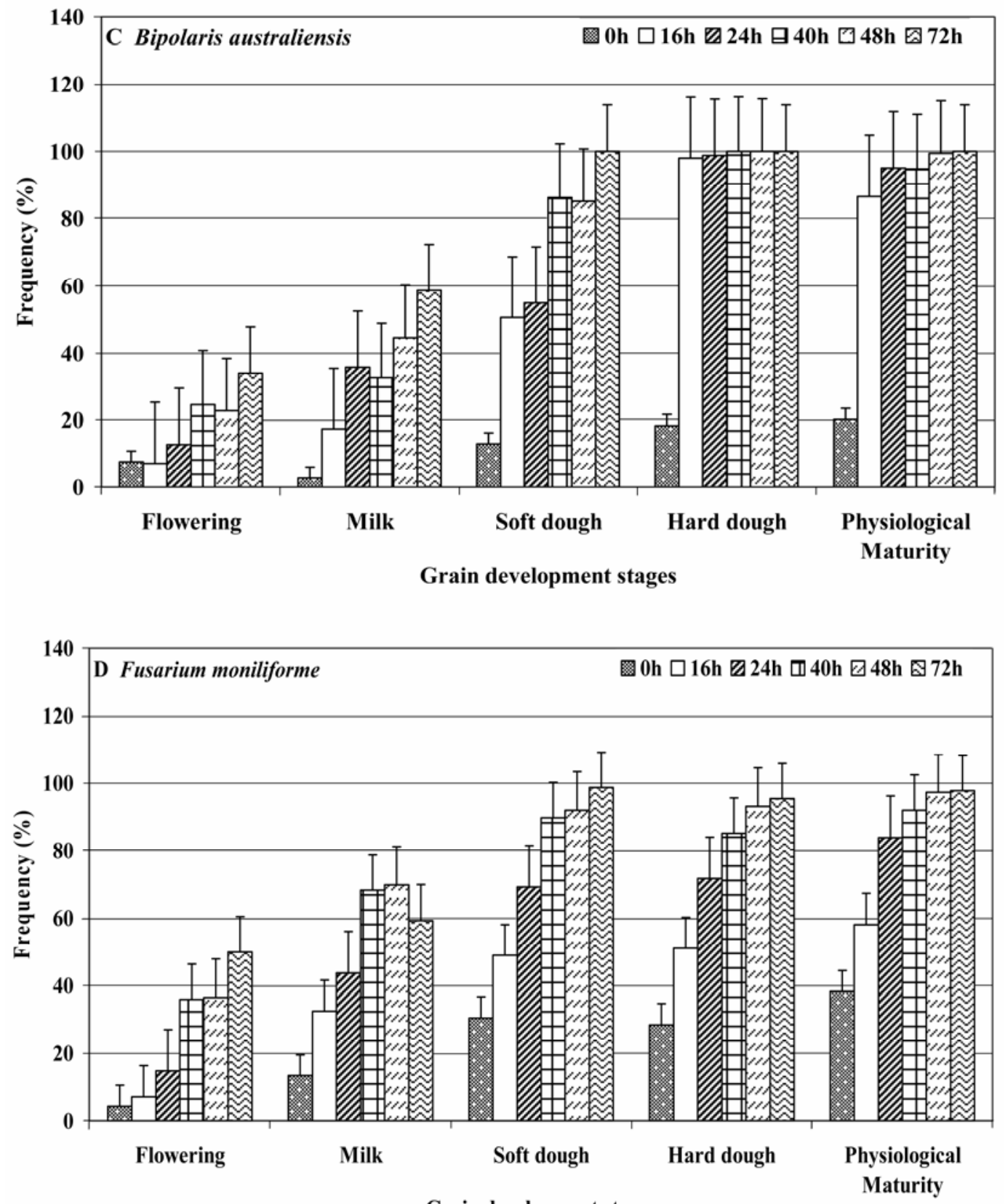

Fig. 1. (Continued on next page) 
development stages than at later grain development stages (Fig. 1D).

Infection frequency of $\boldsymbol{F}$. pallidoroseum. Unlike in other fungi mentioned above, the mean infection frequency of $F$. pallidoroseum was much less in panicles inoculated at $\mathrm{P}$ stage (Fig. 1E). It was observed that the fungus required $40 \mathrm{~h}$ of wetness for maximum infection frequency at $\mathrm{H}$ and $\mathrm{P}$ stages compared with other grain development stages where the infection frequency increased with an increase in wetness (Fig. 1E).

Infection frequency of $\boldsymbol{P}$. sorghina. The infection frequency of $P$. sorghina did not change much with increased WD from 16 to $72 \mathrm{~h}$ in panicles inoculated at $\mathrm{H}$ and
$\mathrm{P}$ stages, indicating that $P$. sorghina requires less wetness at later grain development stages than at early stages (Fig. 1F). However, there was major change in infection frequency of $P$. sorghina in panicles inoculated at $\mathrm{P}$ than at $\mathrm{F}$ stages (Fig. 1F).

Interestingly, there was variation in infection percentage due to $P$. sorghina within the WD. In addition, there was a sudden increase in infection from $26 \%$ at zero WD to $85 \%$ at $16-\mathrm{h}$ WD. Subsequently, there was $88 \%$ infection at $24-\mathrm{h} \mathrm{WD}, 93 \%$ at 40 -h WD, $82 \%$ at $48-\mathrm{h}$ WD, and $96 \%$ at $72-\mathrm{h}$ WD. Reduction of $10 \%$ infection at $48 \mathrm{~h}$ followed by an increase of $14 \%$ infection at $72 \mathrm{~h}$ makes this difficult to explain the behavior of $P$. sorghina (Fig. 1F).
Regressions between WD, grain development stage, and mold infection. With infection at early grain development stages ( $\mathrm{F}$ and $\mathrm{M}$ ), all six fungi showed a linear relationship with WD (Fig. 2A and B). At $\mathrm{S}$ stage, the monomolecular model was adjusted to $C$. lunata and $P$. sorghina, while a linear model was adjusted to the other five fungi (Fig. 2C). All six fungi at the $\mathrm{H}$ stage and $B$. australiensis, C. lunata, Cladosporium oxysporum, F. moniliforme, and $F$. pallidoroseum at $\mathrm{P}$ stage showed a monomolecular relationship (Fig. 2D and E); however, $P$. sorghina at $P$ stage showed a logit relationship (Fig. 2E).

Later grain development stages required less WD than early development stages to

(Continued from previous page)
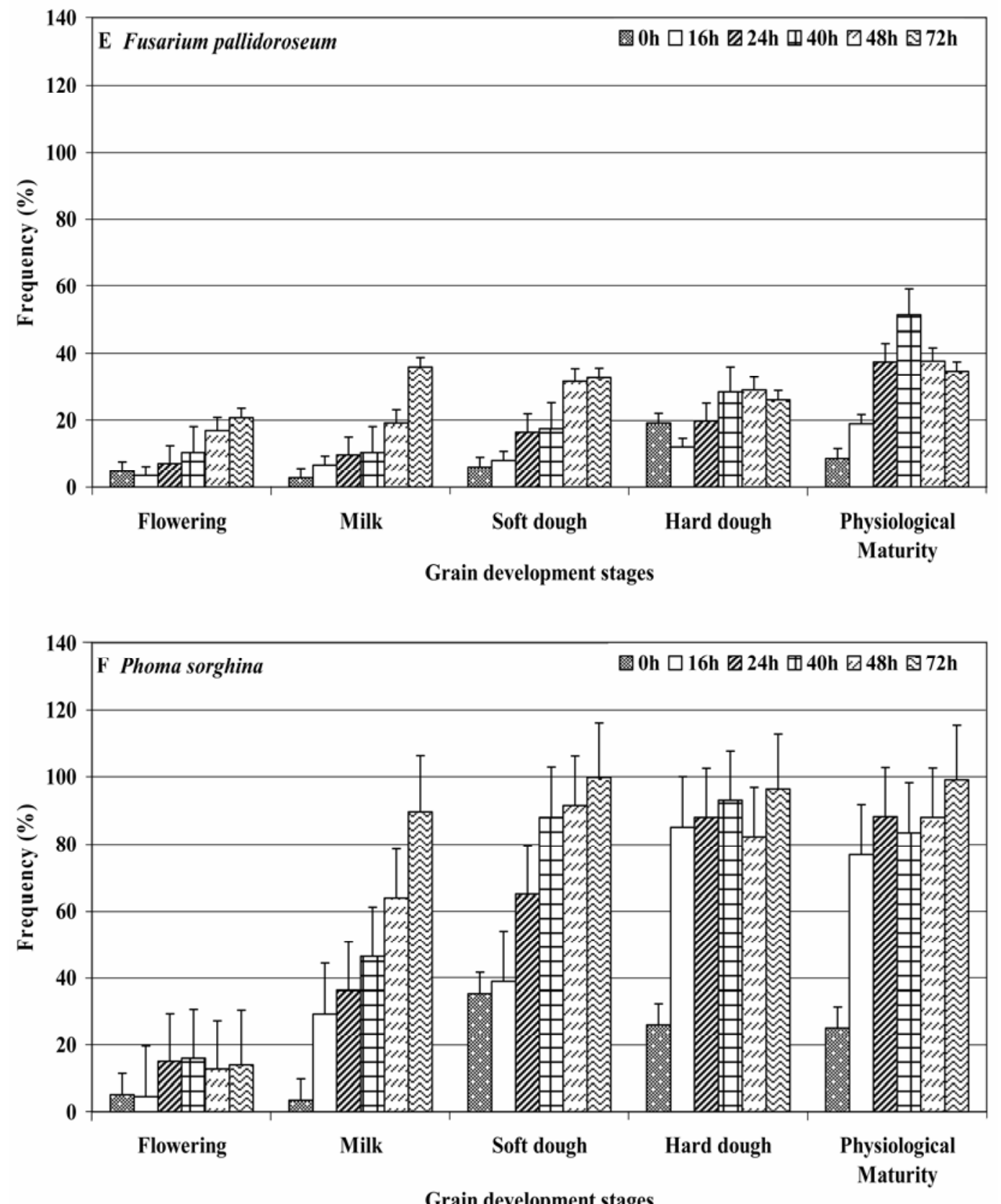

Fig. 1. 
cause similar levels of infection (as indicated in Fig. 2C to E). At S stage, the relationship was monomolecular, logistic, and linear (Fig. 2C), while at $\mathrm{H}$ stage, only monomolecular (Fig. 2D). At P stage, with the exception of $F$. pallidoroseum, all five fungi showed a monomolecular relationship with WD (Fig. 2E). At $\mathrm{M}$ stage, $P$ sorghina and $C$. lunata were more infective after $48 \mathrm{~h}$ wetness than other fungi, and $F$. pallidoroseum produced the least infection (Fig. 2B). At S stage, F. moniliforme, $P$. sorghina, and $B$. australiensis needed less WD than the other three fungi to cause similar levels of infection (Fig. 2C). At $\mathrm{H}$ stage, B. australiensis and $P$. sorghina required as little as $16 \mathrm{~h}$ wetness exposure and produced over $90 \%$ infection (Fig. 2D). At $\mathrm{P}$ stage, all fungi, except $F$. pallidoroseum, were equally infective after $16 \mathrm{~h}$ of wetness (Fig. 2E).

\section{DISCUSSION}

Information on relationships between weather and grain mold could be used to improve techniques to screen for resistance; for example, the use of mist to provide good infection conditions has already been used in ICRISAT. The identification of partial resistance or tolerance may require moderate disease pressure, which could be achieved by manipulating the environment. The effect of canopy structures, such as height and density, and pani- cle architecture both affect the microclimate of the developing grain and periods of surface wetness in the panicle. Attempts should be made to combine these physical phenotypic characteristics with other forms of resistance, such as antifungal proteins.

Fungal colonization of physiologically matured sorghum grain produces a distinct set of symptoms compared with early grain development stages in the field. Colonization occurs primarily on the exposed part of the grain and may be limited to that area. Postmaturity colonization generally produces the moldy appearance of grain maturing in humid environments.

The results showed that $C$. lunata, $P$. sorghina, $F$. moniliforme, and $B$. australiensis appeared to be major mold pathogens infecting sorghum grains at $M$ and $\mathrm{S}$ stages. Similar observations were made in the field studies (20). A WD of 40 $\mathrm{h}$ was optimal for most fungi studied in causing infection. To induce good levels of infection in the field, resistance-screening methods should provide $40 \mathrm{~h}$ of continuous panicle wetness during $\mathrm{M}$ to $\mathrm{H}$ stages.

In the case of $B$. australiensis, unlike $C$. lunata and Cladosporium oxysporum, the infection (\%) was consistent with increased WD and growth stages. In $F$. moniliforme, except in the $\mathrm{S}$ stage, the infection (\%) was consistent with increased WD and other growth stages, while in $F$. pallidoroseum except at $\mathrm{M}$ stage, infection (\%) was consistent at all other grain development stages. However, infection percentage of $P$. sorghina was not consistent due to reasons we could not measure. As was observed in C. lunata, Cladosporium oxysporum, and $B$. australiensis, the infection frequency of $F$. moniliforme was lower in panicles inoculated at early grain development stages than at later stages (Fig. 1D).

Differences between early infections and post-P colonization can be difficult to substantiate in the field. Both conditions occur together, and late-season colonization can mask symptoms of infection during grain development. However, damage caused by mold fungi, various techniques of evaluation for mold resistance, relationship of mold severity and damage, mycotoxins, head bug damage and its interaction in grain mold complex and various mold management options has been discussed by Bandyopadhyay et al. (2).

Bandyopadhyay et al. (2) have indicated also that improved knowledge on disease epidemiology and information on tolerant varieties will be valuable tools for advising on management options in sorghum production and marketing. For example, a mold risk model based on weather can forecast the occurrence and severity of mold in different sorghum-growing areas. Such a forecast system can aid market intelligence to determine the availability of
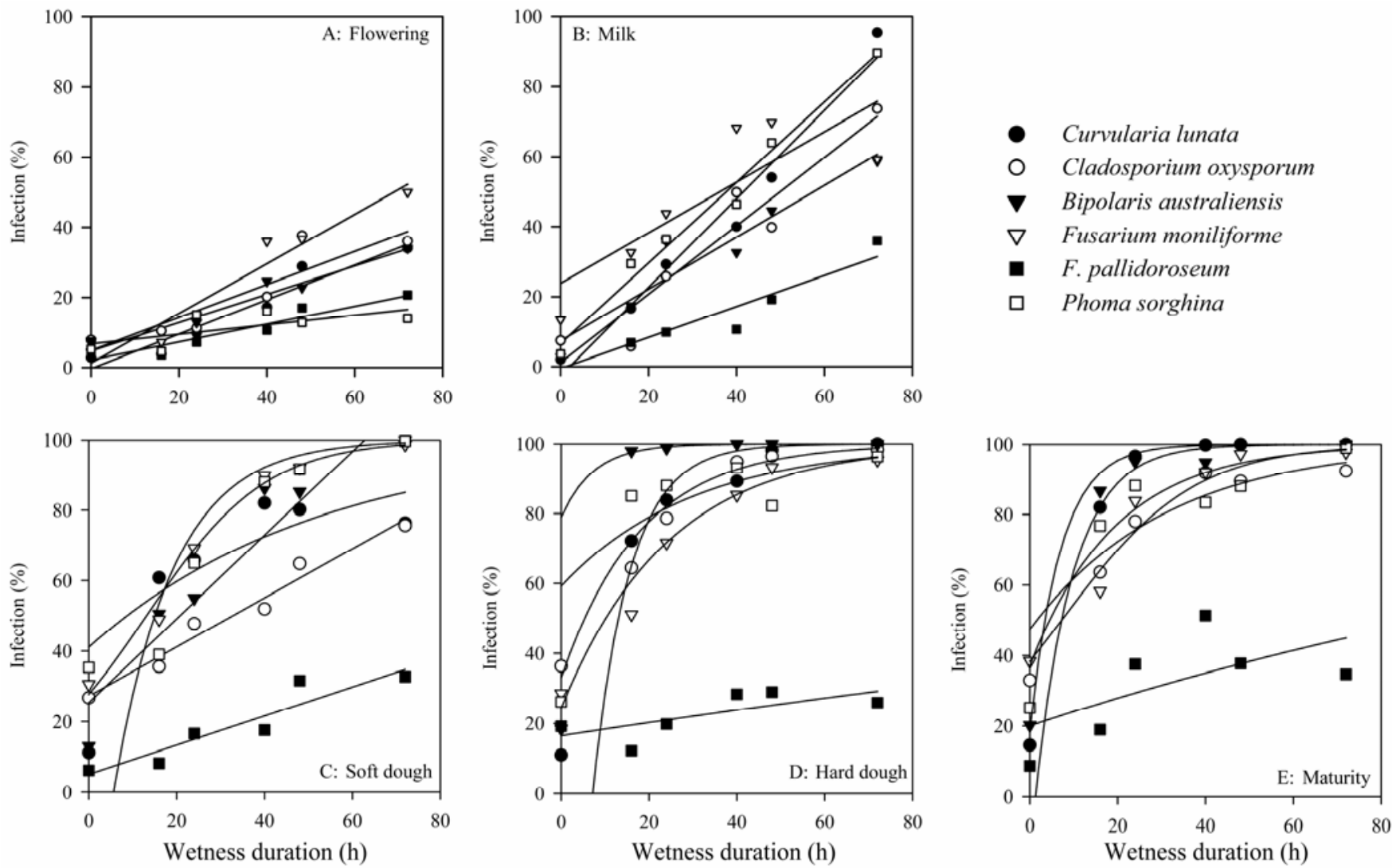

Fig. 2. Regression analysis for the relationship between panicle wetness duration and grain infection (\%) by Curvularia lunata, Cladosporium oxysporum, Bipolaris australiensis, Fusarium moniliforme, F. pallidoroseum, and Phoma sorghina in sorghum line IS 10513 inoculated at A, flowering; B, milk; C, soft dough; D, hard dough; and E, physiological maturity stages. 
sorghum of different quality standards that can be subsequently verified by groundtruthing. Such a method may reduce search cost of sorghum grains of a predetermined standard in markets.

It is possible that under favorable weather conditions, infection occurs between flowering and hard dough; subsequently, if weather conditions are unfavorable toward maturity, mold symptoms may not be visible while the fungi remain inside the grain. Therefore, from the consumers' point, occurrence of infection in early grain development stages appears more critical than symptom expression seen in later stages of grain development.

Future research on infection should focus on interaction between wetness and temperature. Similar information is required for colonization and sporulation phases of grain mold disease to enable development of risk assessment models of different high-yielding cultivars in different rainfall areas. More information is needed on sorghum grain mold epidemiology, particularly on the following aspects: (i) interaction between wetness and incubation temperature on mold infection, (ii) effect of relative humidity levels on grain mold symptom development, and (iii) evaluation of sorghum genotypes with varied resistance under natural, dry conditions while providing mist from not only $\mathrm{M}$ to $\mathrm{P}$ stages but also $\mathrm{H}$ to post-P stages.

Determination of these factors in association with weather factors might provide insights to develop risk assessment models. Results from this work and others are a step in that direction. These would be of value in assessing the risk of sorghum grain mold in different locations, which could be used to advise on suitable sorghum varieties for planting. If the risk of grain mold is low, high-yielding, susceptible varieties may be most suitable, whereas resistant varieties (which may have other disadvantages) should be sown in high-risk areas.

\section{LITERATURE CITED}

1. Anonymous. (Current) R. E. Drennan Home Inspection. 10 South St. Great Barrington, MA.

2. Bandyopadhyay, R., Butler, D. R., Chandrashekar, A., Reddy, R. K., and Navi, S. S. 2000. Biology, epidemiology, and management of sorghum grain mold. Pages 34-71 in: Technical and Institutional Options for Sorghum Grain Mold Management: Proceedings of an International Consultation. A. Chandrashekar, R. Bandyopadhyay, and A. J. Hall, eds. International Crops Research Institute for the Semi-Arid Tropics, Patancheru 502 324, Andhra Pradesh, India.

3. Bandyopadhyay, R., and Mughogho, L. K. 1988. Evaluation of field screening techniques for resistance to sorghum grain molds. Plant Dis. 72:500-503.

4. Bhat, R. V., Shetty, H. P. K., Amruth, R. P., and Sudershan, R. V. 1997. A food borne disease outbreak due to the consumption of moldy sorghum and maize containing fumonisin mycotoxins. J. Toxicol. Clin. Toxicol. 35:249-255.

5. Bhat, R. V., Shetty, H. P. K., and Vasanthi, S. 2000. Human and animal health significance of mycotoxins in sorghum with special reference to fumonisins. Pages 107-115 in: Technical and Institutional Options for Sorghum Grain Mold Management: Proceedings of an International Consultation. A. Chandrashekar, R. Bandyopadhyay, and A. J. Hall, eds. International Crops Research Institute for the SemiArid Tropics, Patancheru 502 324, Andhra Pradesh, India.

6. Castor, L. L. 1981. Grain mold histopathology, damage assessment and resistance screening within Sorghum bicolor (L.) Moench lines. Ph.D. diss. Texas A\&M University, College Station.

7. Castor L. L., and Frederiksen, R. A. 1980. Fusarium and Curvularia grain molds in Texas. Pages 93-102 in: Sorghum Diseases, A World Review. J. Williams et al., eds. International Crops Research Institute for the SemiArid Tropics, Patancheru, India.

8. Castor, L. L., and Frederiksen, R. A. 1982. Grain deterioration in sorghum. Pages 163-169 in: Proc. Int Symp. Sorghum Grain Quality, Patancheru, A. P. India. L. W. Rooney, D. S. Murty, and J. V. Mertin, eds. International Crops Research Institute for the Semi-Arid Tropics, Patancheru, India.

9. Esele, J. P., Frederiksen, R. A., and Miller, F. R. 1993. The association of genes controlling caryopsis traits with grain mold resistance in sorghum. Phytopathology 83:490-495.
10. Forbes, G. A., Bandyopadhyay, R., and Garcia, G. 1992. A review of sorghum grain mold Pages 265-272 in: Sorghum and Millets Diseases: A Second World Review. W. A. J. de Milliano, R. A. Frederiksen, and G. D. Bengston, eds. International Crops Research Institute for the Semi-Arid Tropics (CP738), Patancheru, 502 324, Andhra Pradesh India.

11. Hodges, R. J., Hall, A. J., Jayaraj, K., Jaiswal, P., Potdar, N., Yoganand, B., and Navi, S. S. 1999. Quality changes in farm-stored sorghum grain grown in wet or dry season in South India - A technical and social study, NRI Report 2412, Natural Resources Institute, Central Avenue, Chatham Maritime, Kent ME4 4TB, U. K. and DFID April 1999. pp. 33.

12. Ibrahim, O. E., Nyquist, W. E., and Axtell, J. D. 1985. Quantitative inheritance and correlations of agronomic and grain quality traits of sorghum. Crop Sci. 25:649-654.

13. ICRISAT. 1992. Medium Term Plan 1994 Research theme datasets. Vol. 3. International Crops Research Institute for the Semi-Arid Tropics, Patancheru 502 324, Andhra Pradesh, India.

14. Leslie, J. F. 1999. Genetic status of the Gibberella fujikuroi species complex. Plant Pathol. J. 15:259-269.

15. Maiti, R. K., Raju, P. S., and Bidinger, F. R. 1985. Studies on germinability and some aspects of preharvest physiology of sorghum grain. Seed Sci. Technol. 13:27-35.

16. Navi, S. S., Bandyopadhyay, R., Hall, A. J., and Bramel-Cox, P. 1999. A pictorial guide for the identification of mold fungi on sorghum grain. Inf. Bull. 59 (in Eng, Fr). International Crops Research Institute for the Semi-Arid Tropics, Patancheru 502 324, Andhra Pradesh, India.

17. Rooney, L. W., and Serna-Saldivar, S. O. 1991. Sorghum. Pages 233-270 in: Handbook of Cereal Science and Technology. K. J. Lorenz and K. Kulp, eds. Marcel Dekker Inc., New York.

18. Singh, S. D., and Navi, S. S. 2001. An in vitro screening technique for the identification of grain mold resistance in sorghum. Indian Phytopathol. 54:35-39.

19. Somani, R. B., and Indira, I. 1999. Effect of grain molds on grain weight in sorghum. J. Mycol. Plant Pathol. 29:22-24.

20. Thakur, R. P., Rao, V. P., Navi, S. S., Garud, T. B., Agarkar, G. D., and Bhat, B. 2004. Sorghum grain mold - variability in fungal complex. Int. Sorghum Millets Newsl. 44:104-108.

21. Williams, R. J., and Rao, K. N. 1981. A review of sorghum grain molds. Trop. Pest Manage. 27:200-211. 